being a less hackneyed letter than Euler's $\phi$, which bas no claim to preference over any other letter of the Greek alphabet, but rather the reverse.

It is easy to prove that the half of any perfect number must exceed in magnitude its totient.

Hence, since $\frac{3}{2} \cdot \frac{5}{4}$ is less than 2 , it follows that no odd two-fold perfect number exists.

Similarly, the fact of $\frac{3}{2} \cdot \frac{7}{6} \cdot \frac{\text { II }}{\text { IO }}$ being less than 2 is sufficient to show that 3,5 must be the two least elements of any three-fold perfect number; furthermore, $\frac{3}{2} \cdot \frac{5}{4} \cdot \frac{17}{16}$ being less than 2 , shows that I I or I 3 must be the third element of any such number if it exists ${ }^{1}$-each of which hypotheses admits of an easy disproof. But to disprove the existence of a four-fold perfect number by my actual method makes a somewhat long and intricate, but still highly interesting, investigation of a multitude of special cases. I hope, numine favente, sooner or later to discover a general principle which may serve as a key to a universal proof of the non-existence of any other than the Euclidean perfect numbers, for a prolonged meditation on the subject has satisfied me that the existence of any one such-its escape, so to say, from the complex web of conditions which hem it in on all sides-would be little short of a miracle. 'Thus then there seems every reason to believe that Euclid's perfect numbers are the only perfect numbers which exist!

In the higher theory of congrusnces (see Serret's "Cours d'Algèbre Supérieure") there is frequent occasion to speak of " a number $n$ which does not contain any prime factor other than those which are contained in another number M."

In the new nomenclature $n$ would be defined as $a$ number whose elements are all of them elements of $\mathrm{M}$.

As $\tau \mathrm{N}$ is used to denote the totient of $\mathrm{N}$, so we may use $\mu \mathrm{N}$ to denote its multiplicity, and then a well-known theorem in congruences may be expressed as follows.

The number of solutions of the congruence

is

$$
x^{-}-\mathrm{I} \equiv \circ(\bmod \mathrm{P})
$$

$2^{k \mathrm{P}}$ if $\mathrm{P}$ is odd,

$2^{\mu \mathrm{P}-x}$ if $\mathrm{P}$ is the double of an odd number,

$2^{\mu \mathrm{P}} \quad$ if $\mathrm{P}$ is the quadruple of an odd number,

and $2^{\mu \mathrm{P}+\mathrm{x}}$ in every other case.

In the memoir above referred to, Euler says that no one has demonstrated whether or not any odd perfect numbers exist. I have found a method for determining what (if any) odd perfect numbers exist of any specified order of manifoldness. Thus, e.g., I have proved that there exist no perfect odd numbers of the 1st, 2nd, $3 \mathrm{rd}$, or 4 th orders of manifoldness, or in other words, no odd primary, binary, ternary, or quaternary number can be at perfect number. Had any such existed, my method must infallibly have dragged each of them to light ${ }^{2}$

In connection with the theory of perfect numbers I have found it useful to denote $p^{i}-\mathrm{I}$ when $p$ and $i$ are left general as the Fermatian function, and when $p$ and $i$ have specific values as the $i$ th Fermatian of $p$. In such case $p$ may be called the base, and $i$ the index of the Fermatian.

1 3, 5, 7 can never co-exist as elements in any perfect number as shown by

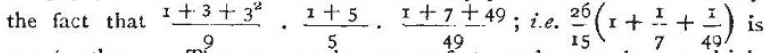
greater than 2. Thus we see that no perfect number can be a multiple of 105. So again the fact that $\frac{5}{4} \cdot \frac{7}{6} \cdot \frac{\mathrm{II}}{10} \cdot \frac{\mathrm{I}}{\mathrm{I2}} \cdot \frac{17}{16} \cdot \frac{19}{18}$ is less than 2 is sufficient to prove that any odd perfect number of multiplicity less than 7 must be divisible by 3 .

2 I have, since the above was in print, extended the proof to quinary numbers, and anticipate no difficulty in doing so for numbers of higher degrees of multiplicity, so that it is to be hoped that the way is now paved towards obtaining a general proof of this falmary theorem.
Then we may express Fermat's theorem by saying that either the Fermatiun itself whose index is one unit below a given prime or else its base must be divisible by that prime. ${ }^{1}$

It is also convenient to speak of a Fermatian divided by the excess of its base above unity as a Reduced Fermatian and of that excess itself as the Reducing Factor.

The spirit of my actual method of disproving the existence of odd perfect numbers consists in showing that an $n$-fold perfect number must have more than $n$ elements, which is absurd. The chief instruments of the investigation are the two inequalities to which the elements of any perfect number must be subject and the properties of the prime divisors of a Reduced Fermatian with an odd prime index.

New College, November 28.

J. J. Sylvester.

\section{COUTTS TROTTER.}

A GREAT calamity has fallen on the University of A Cambridge and on Trinity College, and many men differing widely in their interests and callings are bearing together the burden oi a common sorrow in the knowledge that the Rev. Coutts Trotter, the Vice-Master of Trinity College, was no more. Mr. Trotter suffered from a severe and prolonged illness during last winter and early spring, and though in the summer he seemed to have almost regained his health, he began as the year advanced once more to lose ground. When he returned from abroad in October his condition gave rise to great anxiety among his friends; as the term went on he grew worse rather than better; and an attack of inflammation of the lungs rapidly brought about the end, which took place in his rooms in College, in the early morning of Sunday, December 4.

During the last twenty of the fifty years of Mr. Trotter's life both the University of Cambridge and Trinity College have undergone great and important changes. In bringing about these changes $\mathrm{Mr}$. Trotter had a great share, perhaps a greater share than any other individual member of the University; and while those changes are probably neither wholly good nor wholly evil, but good mixed with evil, no one hand, as the changes were being wrought, did so much good and so little evil as his. A wide and yet accurate knowledge of many different branches of learning, a genuine sympathy with both science and scholarship, a judicial habit of mind which enabled him to keep in view at the same time broad issues and intricate details, a clear insight into the strength and weakness of academic organization, and a singular skill in drafting formal regulations, - these qualities, aided by a kindly courtesy which disarmed opponents, and a patience which nothing except perhaps coarse rudeness could ruffle, enabled him in his all too short life to do for his College and for his University more than it seemed possible for one man to do.

The academic labours which thus year by year increased upon him, though they in many ways, both directly and indirectly, tended to the advancement of science, became, increasingly, hindrances to his pursuing actively any special path of scientific inquiry, as he had once hoped to do. His love of science began with his boyhood, while he listened to the Royal Institution lectures of Faraday. Having taken a degree, with honours in both classics and mathematics, and having obtained a Fellowship at Trinity, he gave up to scientific study much of the leisure thus afforded to him : and, in order more thoroughly to train himself, spent the best part of two years at Heidelberg, during a portion of which time he was engaged in physiological research under Helmholtz. He acquired a very

${ }^{x}$ So to we may state the important theoren that if an element of a mast be its square. 
considerable knowledge of chemistry and botany, but afterwards confined his attention more especially to physics, and lectured experimentally on this subject for several years in Trinity College. In his earlier days he was an enthusiastic Alpine climber, and this led him to direct his knowledge of physics towards the solution of glacial problems. He commenced a few years ago, in the ice-caves of Grindelwald, a series of observations on the physical properties of ice, some of the initial results of which were communicated to the Royal Society. $\mathrm{He}$ was never able, however, to continue, much less to complete, these observations, and perhaps the cruellest feature to him of his illness last winter was that it prevented him from spending the Christmas vacation at Grindelivald, as he had hoped to do, in carrying on measurements of ice, under the most natural conditions, in the depths of an ice-cave.

But the gain to science from Trotter's life is not to be measured by his formal contributions to scientific literature. He had a great unwillingness to write "papers." Though he served for several years as one of the secre. taries, and at the time of his death was President, in the second year of office, of the Cambridge Philosophical Society, whose very life consists in scientific research, and though in the discussions at the meetings he frequently made his critical power felt, his name does not often appear in the Society's publications. He was especially interested in physiological optics, but, though he made many observations, was always disinclined to commit his results to paper. His real scientific usefulness is to be seen in his University and College work. The recent development of natural science (other than mathe. matical) at Cambriclge is coincident in time with, and in great measure clue to, Trotter's academic activity.

In the encouragement given at 'Trinity to natural science, in all the changes of University ordinances tending to encourage scientific research, and to place the teaching of science on a broader and firmer basis, it is easy to trace his hand. He did not always have his own way, and often thought it prudent to accept an arrangement the shortcomings of which he clearly saw ; but his influence, becoming more and more powerful year by year, was always exerted to promote the growth of science in the University, for he at least had no doubt that he was thus working for the welfare both of the University and of his College. He had such a firm grasp of the dominant ideas, and was so wholly in touch with the spirit, of almost every one of the various branches of science, that each teacher and worker sought his help and trusted in his counsel. On the other hand, his conspicuous sympathy with literature and art enabled him to win from those who were strangers to science an assent which would have been denied to claims advocated by others. Happily, too, his singularly catholic mind and temper were made still more potent by a remarkable skill in handling details and conducting business. Were Maxwell now alive, he would be able to tell, as Rayleigh and Thomson can tell, how great a help Trotter was to the Cavendish Laboratory and to physics. The Regius Professor of Physic knows how often Trotter's great knowledge of the needs of medicine on the one hand, and of the capabilities of academic organization on the other, as well as his legislative ability, were of signal service in the difficult deliberations of the Board of Medical Studies. Liveing can say how much not only the very existence, but the details of construction, of the new Chemical Laboratory are due to Trotter's co-operation with himself, and Stuart will tell a like story about the Engineering School. Each science in turn brought its wants to Trotter, and seldom brought them in vain. He recognized Frank Balfour's powers as early as I did, and did more for him in his College and in the University than I could do. All my younger friends whom I am proud to think of as once my pupils, who are ma'sing their names known in physiology, in morphology, and in botany, have always looked up to him as a friend who never failed. And, as for myself, whatever I may have done at Cambridge has been done from first to last through him, and could not have been done without him : in him I have lost my oldest, truest, best helpmate.

I first came to know him a year or so before I received my appointment at Trinity College. Happening to pay a visit to Prof. Humphry, I was taken by him to call on "a young Fellow of Trinity interested in science, and especially in physiology, a capital fellow!" That "young Fellow" was Trotter. I saw, even in our brief interview, much in him to draw me to him, and he seemed to see something of the same kind in me, so that when, a year after, a sudden change in all my plans placed me within the walls of 'Trinity, he and I began a friendship which has ceased only with his death. All through the thirteen years during which, while working within the University, I was really outside the University, my every movement was made by and through Trotter; and since I have been Professor my every movement has been made with him. For seventeen years I have been able to make him a partner in my plans; he has shared in my hopes and soothed me in my failures; where I have been successful he has helped, and when I have refused or neglected his counsel I have generally gone wrong. When Balfour was taken I could feel that Trotter was left, and now he is gone too.

But I ought not to thrust these personal matters on the readers of NATURE, and indeed, great as my own loss is, that of Trinity College and of the University is far greater. Those who know the University and knew Trotter will feel at once how great a blow is his death at the present juncture. The University, both in its scientific and in its other work, is straitened for lack of funds: laboratories cannot be built, teachers cannot be adequately paid, research cannot be properly encouraged, because the necessary money is not at hand. At the same time the revenues of the several Colleges are suffering acutely from the depreciation in the value of land, and a movement has been set on foot with the view of diminishing the contributions of the Colleges to the University. If this movement is successful-and its success seems assured by the fact that the new Nember for the University has, in his address to the electors, given a conspicuous pledge that he, with his commanding scientific authority, will support it in Parliament-it will need the wisest and most skilful handling of details to prevent the result proving disastrous to the cause of learning, and especially of scientific learning, in the University. So long as Trotter was alive we felt that we had one in whom devotion to his College was no les; strong than his love for the University and for learning, and we Jooked to him as the man who, trusted alike by the Colleges and by the University, would be found to have skill to steer $u s$ in the difficult way before us. Now, in the darkness of his death, we seem to be driving, without a pilot, straight upon the rocks.

$$
\text { M. FUSTER. }
$$

\section{H. C. F. C.SCHJELLERUP}

THE Danish astronomer Prof. Hans Carl Frederick Christian Schjellerup died at the Copenhagen Observatory on November i3 after a prolonged illness. He was born on February 8, 1827 , at Odense, where his father was a jeweller, and was apprenticed to a watchmaker, but by private study he succeeded in supplementing the education he liad received in his native town so well that he was able to pass the entrance examination at the Polytechnic School of Copenhagen in 1848 . Here he distinguished himself by his mathematical ability, and was able to finish his studies in the course of two years, when he passed the final examination in applied mathematics and mechanics. In $185 \mathrm{I}$ he 